\title{
The African Digital Humanities (ADH) and Alternation on OJS (2018 - ): Innovation, Pan-African Collaboration, and Trans-Continental Integration ${ }^{1}$
}

\section{Johannes A. Smit Denzil Chetty}

\section{Abstract}

This article is a continuation of a condensing of the presentation by Prof J.A. Smit, as the Open Access keynote lecture, of 23 October 2017. Drawing on Michel Foucault's relational explication of the subjective embodied capacity subjective embodied communication - subjective embodied knowledge-power production triad (cf. Smit \& Chetty 2018: 8 - 30), it first explicates its theoretical framework, in terms of the triad's 'external instruments'. This is followed by a systematic exposition of this framework in terms of the opportunities that the African Digital Humanities (ADH) face as at 23 October 2017. From within the institutional framework of the University of KwaZuluNatal, the article briefly expounds the possibilities that are opened up for the $\mathrm{ADH}$ on the Online Journal Management Systems (OJS). This is further done in terms of the conceptualisations of the e-Humanities, or the future of the eHuman in Africa, as we can, at this stage, comparatively, and analogically envision this complex process, as it is happening at the moment, and as it will doubtlessly further expand into a rapidly changing, and high-speed future.

${ }^{1}$ The article is paired with '23/ 25 Years of Alternation, and the African Digital Humanities: Capacity, Communication, and Knowledge-Power', published elsewhere in this issue of Alternation. The main ideas explored in these articles first formed part of the Open Access Lecture, 23 October 2017, Westville Campus, UKZN. Denzil Chetty contributed to the production of the presentation by Prof J.A. Smit, as well as these two articles. 
Keywords: African Digital Humanities (ADH), Alternation, institution of knowledge-power, institutional capacities, intra- and inter-institutional interaction and communication, the stable perspective, the constructivist perspective, contextually-relevant knowledge, e-knowledge-power building, institutional networks, connectivity

\section{Introduction}

In this article, we continue critically-constructive reflections on the how, the 'what happens', or what we may also term, following Michel Foucault's foundational thinking with regard to 'the task of philosophy as a critical analysis of our world' (p. 335f; e.a.), in terms of what we term, the critical production, of our world, and more specifically, our post-colonial and decolonial, Africanising world. With this switch, we acknowledge, that the how, or the processes and procedures of the African Digital Human Sciences are not founded for the cultivation of an outdated, old-style liberal colonising 'analytical' elite, where the colonised system and style caters for the raciallyadvantaged few, and for the phenomenologising knowledge-production of the phenomenologised African other, for consumption by the EU Other.

Rather, it is for a radical production of the African world via empathetic creative, actively engaged, embodied African subjects' inclusive, embodied knowledge-power productions, in relation to active embodied capacity development, and the development of subjective communication systems and networks, especially via digital media, in the era of the eHumanities, and e-Human, via Artificial Intelligence. In pursuit of creating a conceptual platform, for this focus, this article starts off by explicating its theoretical framework, comprising of two main perspectives.

Firstly, the article develops Michel Foucault's relational explication of the subjective embodied capacity - subjective embodied communication subjective embodied knowledge-power production triad (cf. Smit \& Chetty 2018: 8 - 30), in terms of the triad's 'external instruments', laws, structures, ideologies, and institutions, as these are relevant in the African context today, from Digital Humanities perspective.

Secondly, as said in Smit and Chetty (2018a:19-20), Alternation's broad-based interdisciplinary approaches - or its template, so to speak - are driven by critically-constructive problematisations, and contextually-relevant production, and transformation of knowledge, articulated with evidence-based, 
contextually-relevant, empirical research-led teaching and learning. This section of this article briefly reflects on this notion, 'contextual relevance', and how it provides an interpretive lens, whether consciously theorized by participating researchers and authors or not, for research knowledge that is being used in South Africa, and Africa more generally speaking (and also Alternation over the last 25 years). This is in the interest of the goal-directed purposes of 'the production, and transformation of knowledge, articulated with empirical, evidence-based, contextually-relevant research-led teaching and learning'.

The second and third main sections of the article respectively deal with a brief summary of the how, or the available 'external instruments' or manifest 'ensemble of actions', of the Digital Era, and explores a few preliminary initiatives, for a decolonising digital system fit for knowledge production in the African Digital Humanities.

\section{Theoretical Framework \\ 1.1 Institutional Capacity - Communication - Knowledge- Power: The Stable and Constructivist}

In his seminal, Communication Power (2009), and reflecting on 'power in the network society', Manuel Castells (2009:10) points out that 'society is defined around values and institutions, and what is valued and institutionalised, is defined by power relations'. This understanding has both a stable, and a constructivist and developmental, or 'in-movement' transformational, rationale. Institutionally understood, we can interpret this statement in terms of Foucault's (1982) schemas, as follows, i.e. as we separate out Foucault's focus on the body, and the institution. (Cf. fig. 1 and 2 below; cf. also Smit \& Chetty 2018a).

From a stable perspective, or, a perspective on what was inherited as the existing, dominant, and solidified system that was produced under the racist apartheid regime for forty-six years, we have emerged from a system defined by racial values, and institutionalised oligarchic, racial knowledge-power relational networks inside South Africa, with their international tentacles. This calcified racial system created institutions, in terms of its a-human racial and racist values and ideals, and asymmetrically capacitated a white minority of subjects - academics and intellectuals, entrepreneurs and foot soldiers -, in mind, and consciousness, so to speak. This was done through the production 
of a concomitant racially-founded and universally, if not also transcendentally motivated and legitimated racially-defined knowledge-power block, with its own representatives, instruments, vehicles and drivers. Following Castells, and, for our purposes, from education perspective, it was this knowledgepower block that not only 'defined', but actually produced, a racially segregated 'society' that remains still very much in place today. In this endeavor, virtually all the disciplines at the South African Universities became complicit instruments. The result of this period can be empirically observed and evidenced in the material continuation of the asymmetrically raciallyfounded knowledge-production social networks (including academic social networks and journals), in land and property distribution, the actual urban and rural geographies that distinguish between developed infrastructure and underdeveloped (or stunted), the number of productive institutions and companies, together with the large diverse array of cross-cutting para-institutional national and international props and networks.

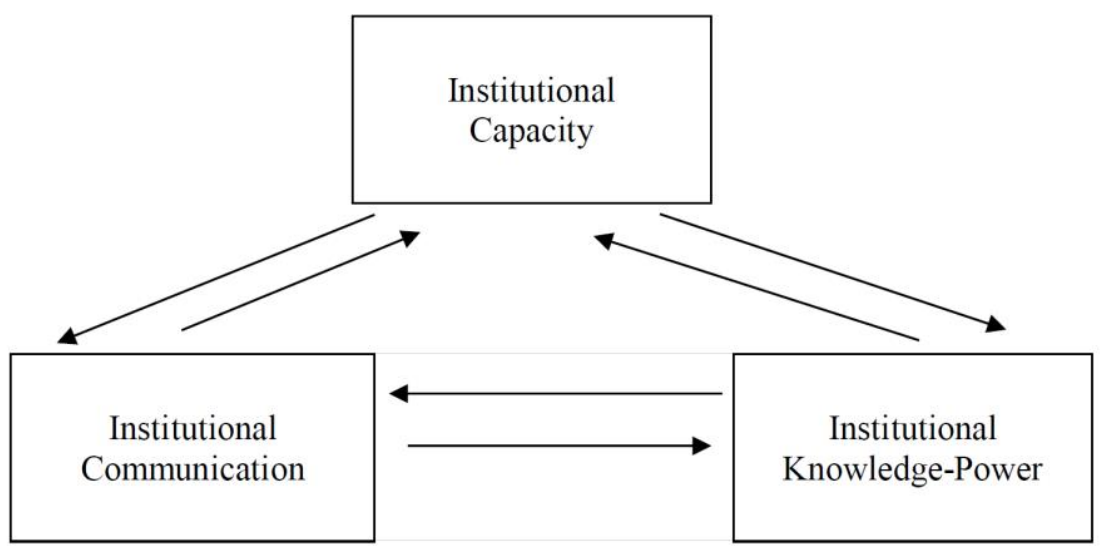

Figure 1: The institution's united, interactive, and integrative relations between capacity, communication, and knowledge-power

In terms of Castells, then, apartheid's racially-defined values, and power relations produced and institutionalized apartheid society. And in terms of Foucault, as already pointed out, via its external 'instruments', inculcating these same values in subjects, both white and black, not least through its, 'laws, structures, ideologies, and institutions' for which the Apartheid education 
systems, and learned societies and intellectuals, were the incubators, if not the internationally maligned and vilified vanguard.

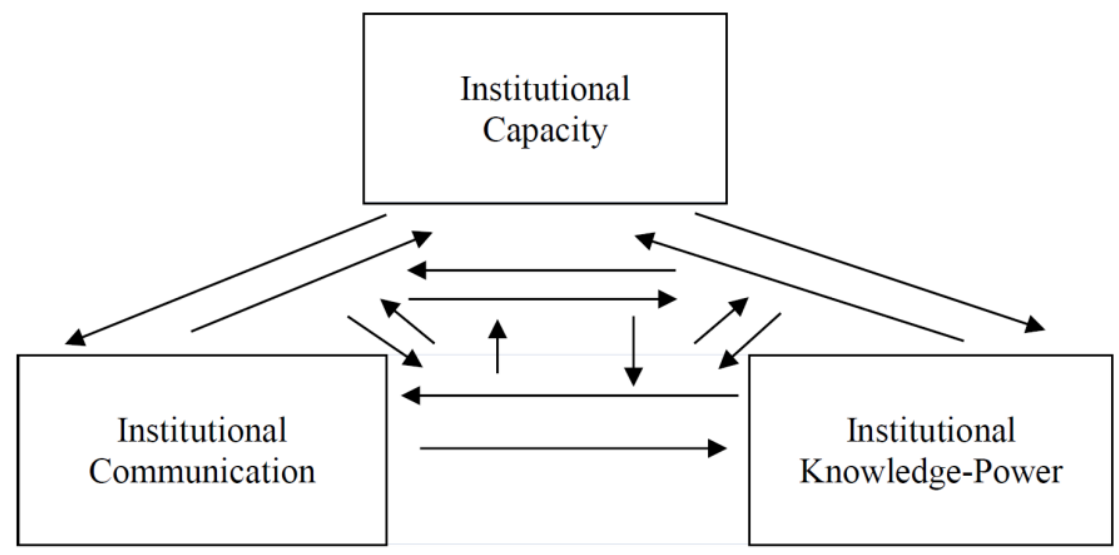

Figure 2: The relations of the relations of the institution's united, interactive, and integrative relations between capacity, communication, and knowledgepower

From the constructivist perspective, the question concerns the changes, or transformations that have taken place in South Africa with regard to the 'laws, structures, ideologies, and institutions', since 1994. On the one hand, and that generatively, much has been changed since 1994. Apartheid's systems of racially motivated laws that generated its values, institutions, and thus, society, were scrapped, and replaced by a democracy with a democratic constitution and the rule of law, and not a racist oligarchy. Concomitantly, the previous racially separated education system was discontinued and replaced with a unitary though diverse, non-racial education system founded on the humanist values of freedom, equality, and social justice. In line with the transformation-oriented Bill of Rights (cf. Smit 2009), many black empowerment systems were created, including the implementation of transinstitutional affirmative action processes and practices, and the Broad-based Black Economic Empowerment (BBBEE). In our modest assessment though, and that from the institutionalised 'capacity - communication - knowledgepower' triad perspective, there has not been sufficient movement in the 
research and knowledge production domains of South Africa. And, on this, we wish to make two points.

Firstly, as yet, we have not fully succeeded in producing a non-racial knowledge-power bock, a block that serves all South Africans equally, irrespective of race and class. (Much remain racially skewed, and that in untransformed ways institutionally, as well as in the substance of programmes, disciplines, and research-based knowledge production.) As is well-known from Foucault's life-long project, such a block would require the requisite discourse (or, knowledge-language, or, contextually-relevant concept) production and discursive formation(s) development. In our humble opinion, from the perspective of the subject, that can only come about through what we have termed 'critically-constructive contextually-relevant problematisations, and production, and transformation of knowledge, articulated with evidencedbased, contextually-relevant research-led teaching and learning' (cf. below). To this we must add, that the broad-based goal for this approach, should be that the knowledge-power block, would directly meet the expectations present in the Constitution, the Bill of Rights, and, most importantly, the people on the ground, and in the street, inside the theoretical framework of the highest level of scientific objectivity and accountability. In terms of this article, it would be populated by African subjects capacitated with the highest levels of scientific knowledge and skills, embedded within non-racial academic communication networks that span the country, continent, and also globally. If we fail to do this, we are not only failing at all the three levels of the Constitution, the Bill of Rights, and the expectations of the citizens of our country, but also the responsiveness of science to human well-being and human need, and human suffering, in South Africa, and more broadly afield, our continent, as well as globally. From this perspective, and in the absence of the requisite knowledgeproduction approaches, by its non-engagement, much in southern African academia remains bleak and barren.

Secondly, and staying with this topic of the Knowledge-Power Block (KPB), we believe that we need to think through its relationship with communication, and adjust Foucault's notion of the 'block' to that of the network, i.e. 'Knowledge-Power-Network' (KPN), in lieu of our entry into the Berners-Lee era in 1989, five years after Foucault's untimely passing. In the era of digital networks - lead by the $w w w$ for instance -, e-publications, information networks, academic media, and information, and data flows, as well as e-communication (including the exploding systems of messaging), we 
should re-think the notion of knowledge, as defined by a stable discipline, inside rigid and unchanging boundaries, with an outdated, irrelevant philosophy, conjoined to similar problematisations and research projects. Thomas Kuhn's classical conceptualisation of the notion of the 'paradigm', and what has also been called the 'paradigm paralysis', comes to mind. Knowledge by definition has always been evolving and been in movement. The only change is the speed with which not only the knowledge systems their infrastructure(s) - have evolved over the last two decades (via $w w w$ for instance), but also the breakneck speed through which digital institutional research, and educational systems of Teaching and Learning have started to explode over the last two or more years, not to mention the quantum leap in algorithm developments and deployments - cf. below.

As such, the constructivist paradigm does not have to account for the values in themselves - that has been done in the Constitution and Bill of Rights. We need to account for their implementation and the material, subjective, embodied, and social realisation, manifestation, and institutionalization of substantive, sound, and conceptually-relevant conceptually-rigorous knowledge, inherent in the subject - communication - knowledge-power - network relations.

So, we should not keep on thinking of knowledge-power as stable, something solidified, and unchangeable, but something that flows in digital information and data networks. Moreover, in terms of our still young South African dispensation, and, Foucault's triad, such a network would be populated by subjects, who are conceptually capacitated from a knowledge-power perspective, to both clearly analyse and comprehend the problematic nexuses

${ }^{2}$ We believe 'paradigm paralysis' to be a major challenge in South African academia. The main hurdle is that some who are supposed to be the leadknowledge producers in the country, are being held captive by an imaginary colonial- and apartheid-inherited paradigm and related practices of not thinking from this space, in the present, by the embodied self, and then to constructively, and creatively engage the South African problematic contexts. This knowledge-practice is steeped in and permeated by the importation of problematisations, and their methods in thought, which are asymmetrical to and not fitting South Africa, and more specifically, African conundrums and conditions, as these have been produced in the closed academic circles of former or foreign, times, and climes for different, non-African populations (cf. Smit 2017:270ff; 2018:11ff). 
in society, and have the mind, body, and emotional skills to constructively, and transformatively engage them. They will also be able to participate in the advances of Artificial Intelligence, and to harness and direct its capacities for self, social and knowledge developments, not only by, with and for Africans, but also internationally. (Cf. 1.3 below for a further explication.)

\subsection{Transformative Contextually-Relevant Knowledge Production: Theory}

In terms of our constructivist question of a critical production of our world not excluding Michel Foucault's question of 'the task of philosophy as a critical analysis of our world' (e.a.) - we want to put forward that this primarily entails the problematisation, research, and requisite knowledge production for our world, e.g., on issues and challenges that South African citizens (including refugees and migrants) face on a daily basis, but also structurally. In order to do this, we need a clear understanding of the notion of 'contextual-relevance'. Over the last fifty-odd years, this notion has been deployed in transdisciplinary ways by many disciplines. It is not our objective to overview or review this history here, also not to go into too much detail. By drawing on Dan Sperber and Deirdre Wilson's 1986 Relevance: Communication and Cognition, we shall just very briefly indicate, the 'how', the 'what happens', when we deploy their theorising for contextually-relevant research purposes, especially in the African Digital Humanities.

In Sperber and Wilson's theorising, cognition, especially as it happens in communication, takes place through utterances (or any kind of sign or stimulus for that matter), which can be either verbal/ heard/ listened to, or read (pp. 6 - 64). On hearing or reading utterances, we can understand them, because we relate them to assumptions that we have about whatever the utterancestimulus is about - 'utterances encode assumptions' (pp. 5, etc.). In order to do this, we need to match a virtually infinite number of assumptions from our general and specialised knowledge domain, or cognitive context, to the utterance, and is only satisfied that we understand it, when we find an assumption that fits. Understood in this way, 'context' is a psychological, and more specifically, a cognitive construct, comprising of a subset, or cluster of assumptions of all the assumptions that we hold about the world, understood in its broadest and most universal sense (p. 15, etc.). These assumptions can be regarded as factual, if, in a specific time and space, or situation, it is possible 
to represent the fact mentally and accepting its representation as true or probably true (pp. 39ff; 16). So, in the mental processing of an utterance in verbal communication, a listener or reader accesses assumptions from her/ his cognitive environment, thereby creating a context in which the utterance (or any stimulus for that matter) is interpreted. The (contextual) assumptions which are chosen mentally to make sense of a stimulus, are determined by the principle of relevance (pp. 118ff; 155ff, 177ff). Sperber and Wilson then explicates this principle, in terms of how it provides humans intersubjectively, with the ability to create contextual effects, i.e. continuous understandings, as well as changes, in the mental contexts, or the body of assumptions that humans share, about the world of facts. For contextually-relevant effects though, for change in the cognitive environments, or mental worlds, or ensemble of assumptions, through which we understand our world(s), including Foucault's notion of 'ensemble of actions', it is important to note that humans continuously both communicate, and access 'new' information, vis-à-vis 'old' information (pp. 122f, 136-141). We shall not go deeper into this explication. Suffice to say that Sperber and Wilson go on to theorise it in greater detail, in terms of context as a psychological construct; the principle of relevance and contextual effects; relevance to an individual - to which we must add 'interpretive community'; ostensive-inferential communication; and the interaction of new and old information ${ }^{3}$. But be that as it may.

For our purposes, it is informative, and helpful, to 1) work with notions of 'assumption', i.e. as in what we assume about our world; 2) the cognitive

${ }^{3}$ We need to note that this very brief explication of the theory in Relevance: Communication and Cognition, is much more detailed, but very clearly set out by Sperber and Wilson. We also need to flag the fact that their theory of contextual relevance has become part and parcel of many Linguistics 101 courses world-wide, and is to be recommended. Cf. also Sperber's comment on relevance (2002: 140); and on 'relevance' of 'conceptual representations' in symbolic language, in Sperber (1974] 1979: 100ff, 119ff). In Meaning and Relevance (2012) Wilson and Sperber have sharpened their argument, i.e. that 'comprehension is a process of inference guided by precise expectations of relevance'. In our assessment, and especially for the ADH, Sperber and Wilson's theorising of relevance have, as yet, merely opened the field of questions, not only with regard to the subject, but also with regard to the esubject, and e-interpretive communities, in the e-communication - eknowledge-power relational networks of the digital age. Cf. below. 
principle of relevance, i.e. as it is used to make mental representations from our cognitive environment, to ourselves, and our communities, about what we regard as true 'facts' about that world; and 3) what they term 'contextualisation'. The latter, which is a very well-known trans-disciplinary notion, they use to indicate the processes through which utterances are brought to understand-ing. They say,

If all a contextualisation does is add all, some or none of the new information to the context without otherwise altering the context at all, then this contextualisation has no contextual effect. Otherwise, there is some contextual effect, in the form of an erasure of some assumptions from the context, a modification of the strength of some assumptions in the context, or the derivation of contextual implications (Sperber and Wilson 1986:117).

This latter explication is obviously helpful with regard to when we deploy it for purposes of knowledge building and transformation. In principle, it explicates the 'how', for the coining and deploying of concepts that are factually true and correct about the cognitive representations about our world - the old information, or in Foucault's terms, the 'analysis of our world' as it is -, as well as the production of new concepts and related assumptions, and cognitions, that are not only factually correct and true about our world, but also true for the creation of the world that is envisioned, or towards which a transformation is conducted. This is the new information. And, for purposes of knowledge transformation, intersubjectively, in interpretive communities, or even, in paralysed paradigms, such an explication is helpful.

\subsection{Transformative Contextually-Relevant Knowledge Production: Praxis}

Taking into consideration the dawn of the Berners-Lee era, and, in our terms, the birth of the e-subject, in e-communication, and e-knowledge-power digital networks, added to the context of the virtual explosion of Artificial Intelligence (AI) systems ${ }^{4}$ and their processes and procedures, we can represent this altered

${ }^{4}$ The most basic understanding of AI, is that it comprises of some or all of the electronic information or data that humans and/ or machines produce and/ or 
system, in terms of Foucault's theorizing as per figure 3 below. In the first place, and, to complement Foucault, we need to add the digital, the electronic, or, as has been recognized of late, the algorithm, to his explication of the subject in terms of the body and institution. If we need to think through his system, in terms of the embodied subject, and/ or the institutionalized/institutionalising subject, we now need to think it through in terms of the e-subject, and more specifically the e-subject algorithm. Once we cross this threshold - which we have done, since the moment we started to electronically store our intellectual productions in electronic files and folders, followed, too, for instance by the first programmes that automatically corrected our typed language on our PCs according to electronically stored dictionaries and thesauri in the early $1990 \mathrm{~s}$ - we have entered the domain of an independent intelligence, i.e. independent of embodied subjectivity, or, a dis-embodied subjectivity, if you will. In terms of Foucault's triad, we can represent it as in figure 3 below.

With the dawn, and multiply embodied experiences of the algorithms, we have progressed beyond the bi-stable representations of colonizer and colonized, for instance. We have entered the universe of the unstable, unpredictable, variable and volatile, which ranges from subjective perceptions, through communication networks, to the challenges for knowledge production, not least within the Human Sciences. Even as the legacies of colonization are still all around us, the e-subject - e-communication - e-knowledge-power systems, modelled after Foucault, has taken us beyond it ${ }^{5}$. Simultaneously, it has opened large vistas of possibility for the humanities, especially for its wide variety of potential in digital or electronic forms. Like the old mine-dumps,

store. It may be stored, packaged, used, or developed in a myriad of ways, ranging from saved files on a Laptop, to working robots, to nano-technology products. It also includes all operations that humans require machines (and smartphones, or other 'gadgets';) to do, rather than using the brain, or human intellect, such as the use of electronic calculators.

${ }^{5}$ For now we may also just mention that the notion of the 'relation of the relations', may also be thought in terms of Sperber and Wilson's notion of relevance, as the principle of the digital relevance, or e-relevance of the relations of the relations of e-capacity - e-communication - e-knowledge-power. At the biochemistry level, and thát, plurally, it could also be thought as clusters of body-algorithms - communication network algorithms - knowledge-power networks, ánd, for that matter, networks of networks, of algorithms. 
that are there in all their materiality and cannot be wished, or washed away, and still polluting rivers and ground water, the legacies of colonization are continuing to seep its poisons and contaminations also into our knowledge formations. Yet, the dawn of the e-subject, e-communication, and eknowledge-power networks, have precisely through their instabilities, and variable systems opened a myriad of possibilities for the e-Human and eHumanities. This has opened possibilities, for e-Knowledge-Power productions, in developing e-Knowledge-Power Networks, especially in the developing and erstwhile colonized world like never before.

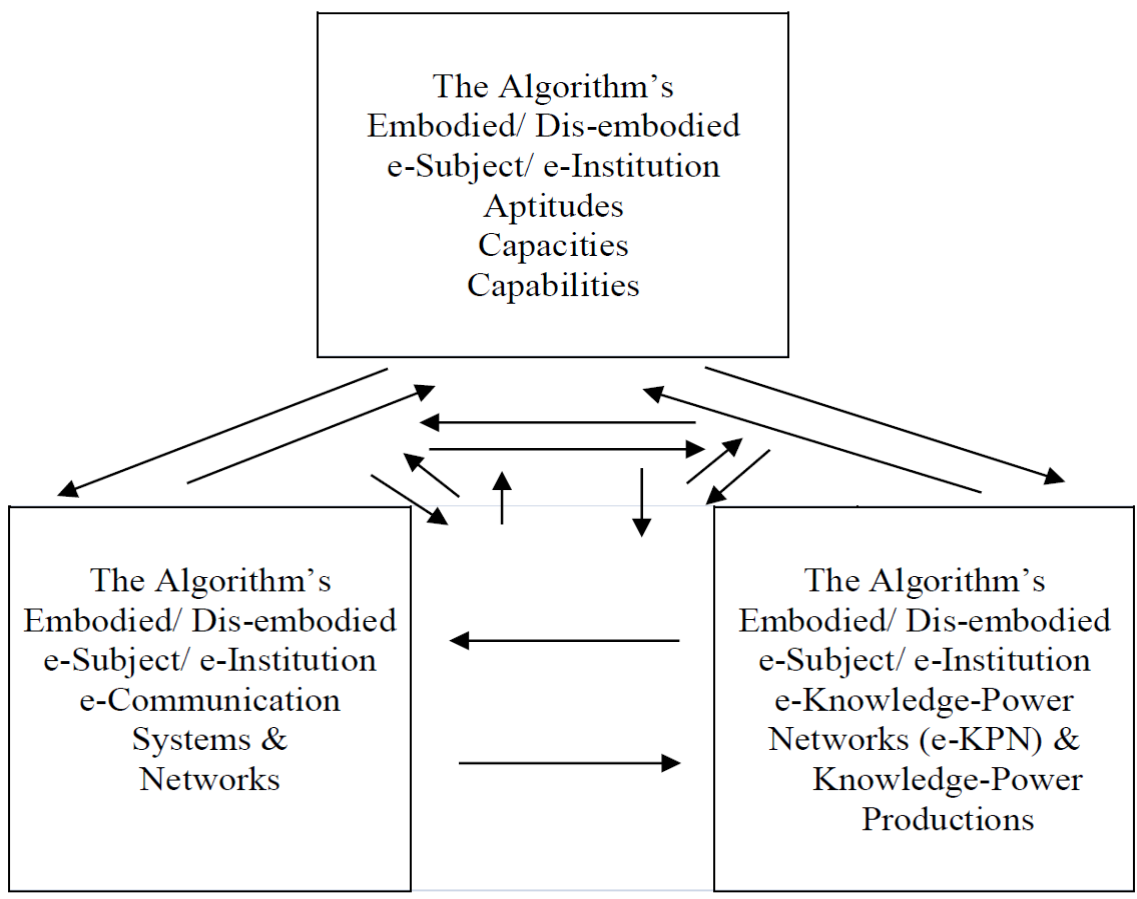

Figure 3: The relations of the relations of the e-Subject's, and e-institution's united, interactive, and integrative relations between capacity, communication, and knowledge-power, from the perspective of the networks of networks of the embodied, and dis-embodied algorithm

On the one hand, this provides opportunities to radically create new knowledges, through developing new knowledge-power e-networks, as well as 
the networks of networks, together with all the opportunities, and challenges that entail - also for the African Digital, or African e-Humanities. Yet, it also provides us with the possibilities to re-work the rejected stable (and archived) knowledge productions of the past - as they are being digitized -, to still see whether there is still something useful, i.e. nuggets of discarded and denigrated information, which just might still be centrally important, even foundationally. In this endeavor, AI has already proven tremendously helpful, going back to the study of the history of our ecological systems, and humanity's oldest biochemical algorithms. As we are producing a new world, or a new Africa of knowledge-power and of human, and ecological value, the re-working of the old knowledge dumps, whether from the colonial era, or from long before that, though, is only part of the challenge. The main challenge remains the objective, to produce the best empirical evidence-based, contextually-relevant knowledges, together with the requisite data and information productions, and interpretations - with the assistance of algorithms or not -, and, to teach that, via evidence-based, research-lead teaching and learning methodologies.

With regard to the praxis of a transformative, and transformed, contextually-relevant knowledge production, the dawn of the algorithm provides immense possibilities and opportunities, for not only personal knowledge and development ${ }^{6}$, but also knowledge production in the e-Humanities more broadly speaking. In the rest of this article, we shall just briefly summarise an example from 2000, of how the knowledge-production networks work, and have been developing, and then provide a sample of perspectives on these processes $^{7}$. Both of these, impact on the two-pronged network development challenges that we face, i.e. Pan-African collaboration, and trans-continental integration.

\section{Knowledge Building Processes}

Granted that knowledge-building processes are heterotopic, multi-stable interlinked networks capturing multiple complexities, the question is how to

${ }^{6}$ In the developing Alternation network, Rembrandt Klopper's 2005a and $2005 \mathrm{~b}$ articles on communication, from the nonverbal to e-communication, were the first to broach this issue. But, on the beginnings of language, see also Richard Bailey (1995).

${ }^{7}$ Note: This is a sample that was used in the Open Access lecture of 23 October 2017. Much has happened since. We add one reference from October 2018. 
understand them ${ }^{8}$. In a nutshell, the argument is that within a sea of information and data productions, disseminations, and flows, it is value-based, or ethical, knowledge-power hubs that provide citizens with ordinary, and close-at-hand, responsive, and responsible means to access useful information and knowledge within the knowledge-power networks. The hubs, comprise of diverse, heterotopic organizing systems and networks that cluster, and compound composite information and knowledge formations from the complexities available, at different levels, arranged in ascending levels of complexity. To render the best service to information and knowledge users and consumers, the generating systems, including the use of algorithms, need to be developed internationally. This, in itself, is a daunting task, but, as we have already learnt and are continuously experiencing, the deployment of algorithms play very useful roles, ranging from the e-subject, through e-communication, to eknowledge-power productions, and digital networking. More than ever before the open vistas for knowledge-power productions in the e-Humanities call for the cooperation of vast arrays of agents and personnel in international, and internationalizing knowledge-power frameworks. As just one example, dating from 2000, we want to flag the factors involved from the contribution Gerry Stahl made to the discussion (cf. figure 4 below).

We have chosen this image because it shows how both the personal and social play a role in the whole process. The one does not exclude the other, and should be seen as integrative. Also important for us, and what we want to complement to Stahl's presentation, is that such a circle should not be regarded as a closed, vicious circle of inclusion and exclusion, but rather as nodal hubs in developing networks of knowledge-power production. So, one hub itself, as it develops to function speedily, efficiently, and optimally with the contribution of its members, also challenges the members that form part of the hub, to feed into further developments of their own networks of choice. Ultimately, from an intellectual and academic level, this means that each subject, or, for that matter, networks of subjects, and networks of networks of subjects, also as they are integrated socially with their communities a la Gerry Stahl below, may have one or more hubs, from within which it operates, or to and with which it is

${ }^{8}$ For a more comprehensive explication of these understandings, see, Smit and Chetty (2018, forthcoming), as: 'Designing Equitable Foundations for Open Knowledge: Access, Freedom, \& e/Quality. Alternation Special Edition 23: 8 -33 . 
articulated ${ }^{9}$. In terms of such and understanding, we can represent PanAfricanity, as per Image 1 below.

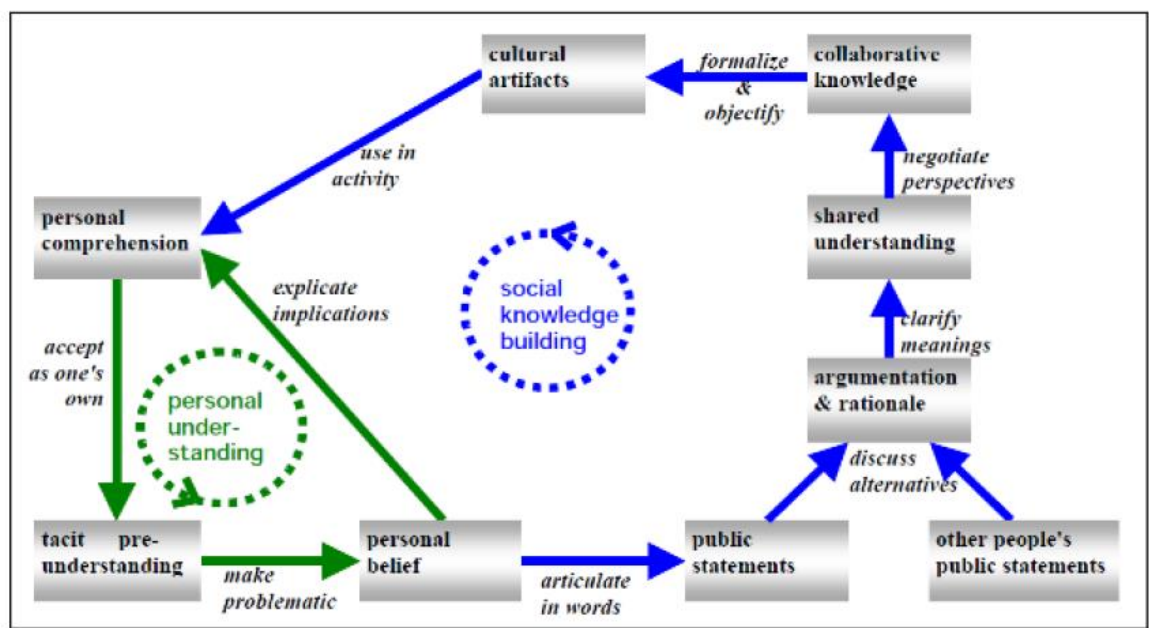

Figure 4: Thinking knowledge-hubs, in the African Digital Humanities (ADH) or African e-Humanities networks, in terms of African Collaborative Knowledge-Building, thought in terms of the framework of Gerry Stahl (2000)

In terms of the so-called Cold War legacy of the world, and how it has asymmetrically impacted Africa, where the various governments of Africa were pushed to make choices between 'the Capitalist West, and the Communist East', it is incumbent for African hubs to not be pushed into making choices of serving one or the other global military-industrial, or for that matter, digital, or e-humanities-knowledge-power complexes, or networks but rather to ask questions concerning their usefulness, with regard to contextually-relevant knowledge-power productions (CRKPP), and teaching and learning in local, and national African contexts. We also believe that contextually-relevant

${ }^{9}$ This would mean that we should also understand figures $1 \& 2$ above, as open triads, or open circles. Internally to countries, especially with regard to governance, we have an example about how it has been developing and is functioning, in Abdulla and McArthur (2018:154 - 186) elsewhere in this issue of Alternation. 
transformation questions should remain integrally part of these processes and procedures. And, we also wish to suggest, that it also means that one should seek connectivities, but not be coerced to become part of knowledge-power systems which do not serve the well-being of the people of the African continent, whether the US, EU (incl. or excl. Britain), Russia, China, or any other national, or globalizing knowledge-power formation, including the religious. In this regard, we believe we should be steered by a broad-based African principle of relevance, not least in e-knowledge-power productions. We further also acknowledge, that even as these knowledge-power productions are indeed meeting relevance principle needs and challenges, that all knowledge produced, remains hybrid, and not pure, similar to the human genome. The question should remain though, of usefulness for development, and the reach, spread, and range of such knowledge-power systems, with regard to it serving the human, and ecological well-being of the planet, irrespective of race, class, gender, or any other socially generative system.

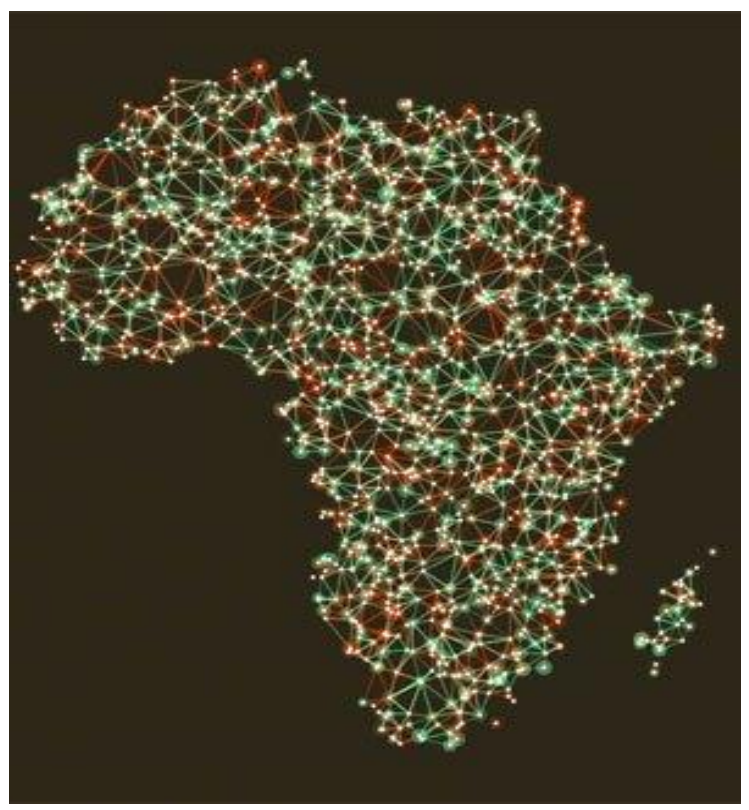

Image 1: Image representing e-knowledge-power production hubs on the African continent. (Image widely available on the internet.) 
Johannes A. Smit \& Denzil Chetty

Globally, the digital connectivities are being represented as in images 2- 5 below.

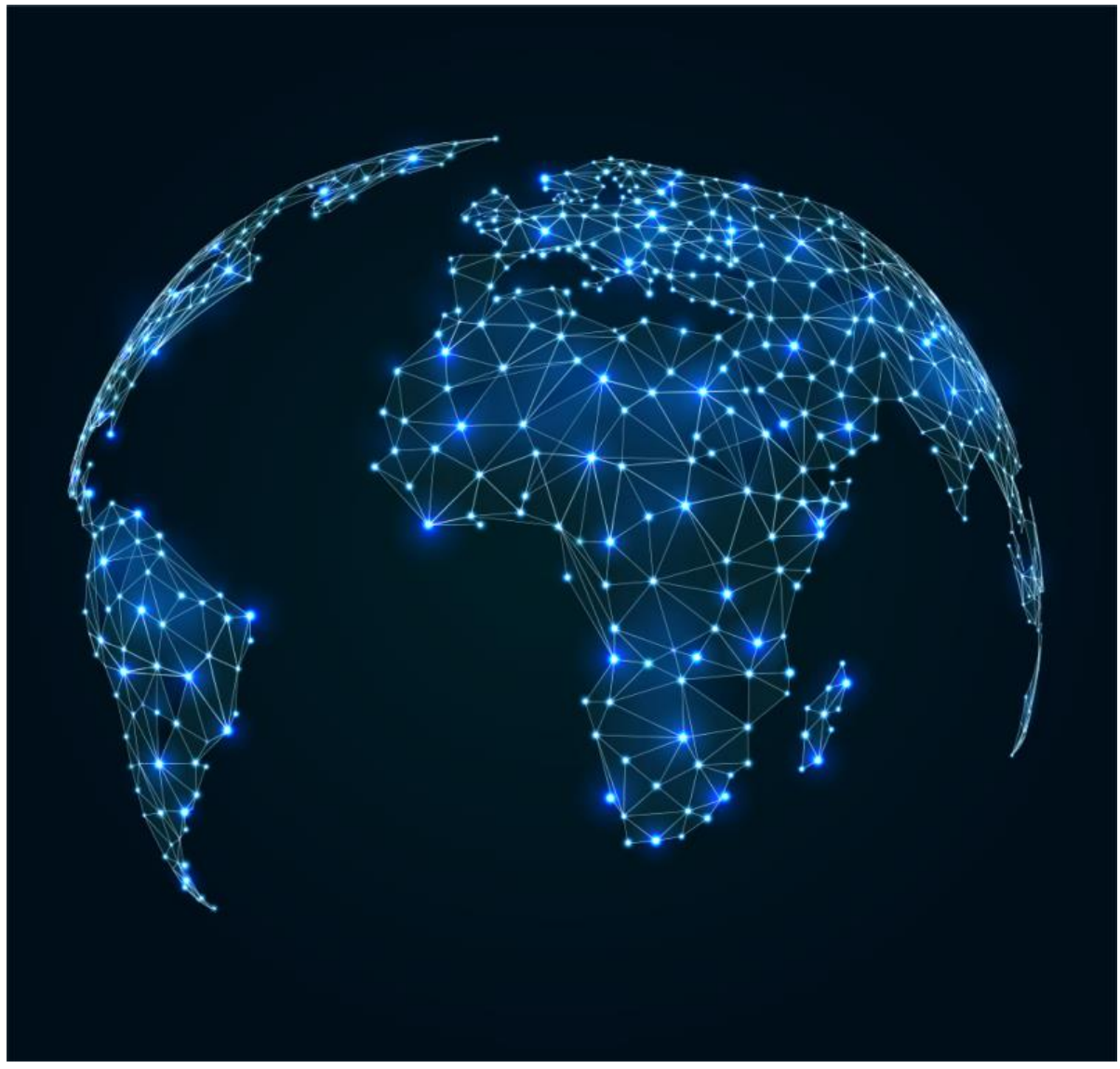

Image 2: Continentally-focused global connectivities internal to the continents, image 1. (Image widely available on the internet.)

Thinking from the perspective of the subject, it involves possibilities and opportunities for self and social advancement, via personal capacity and capability developments, and an alliance with and active involvement in eknowledge-power networks. This is important, and will become ever more 
important, in the presumed future disappearance of traditional pre-digital labour and job market opportunities and systems. It will also very soon involve the training of students and young e-human knowledge-power entrepreneurs in the learning of code and the writing of effective code, to perform AI tasks in solving specific e-human problems, and constructively and efficiently engage e-Humanities conundrums according to personal and social e-relevance principles. This also involves, and might even escalate, the physical movement and studying of young students and knowledge-power entrepreneurs from the African continent to as many on-site parts of the world as possible.

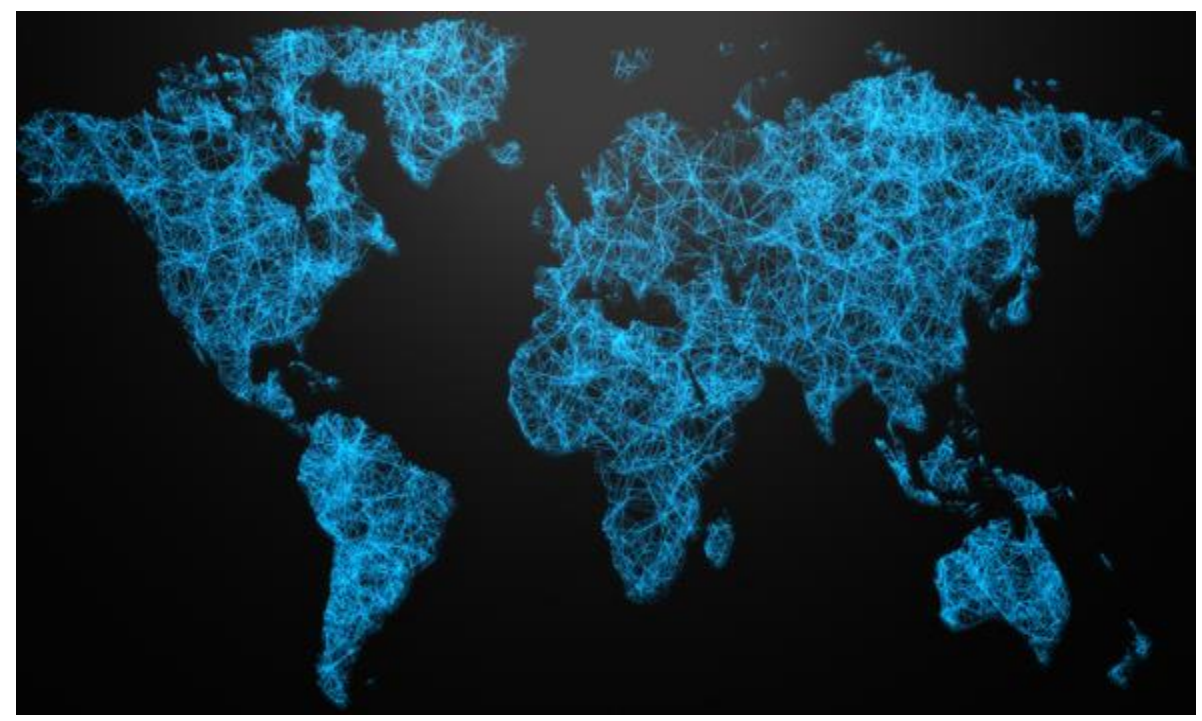

Image 3: Continentally-focused global connectivities internal to the continents, as per image 2. (Image widely available on the internet.)

It is true that with the dawn of virtual classrooms, some have argued that face-to-face classroom contacts have become obsolete. The truth, though, as numerous studies especially from the United States have shown, is that people continue to prefer to physically go to campus, for the social interaction and social learning in itself, that takes place there, and, obviously also for multiple exposures to the on-site, spatial engagements of knowledge transfer, mentoring, and knowledge production, and dissemination in actual geographical spa- 
ces of interaction and knowledge transfers and productions. Conversely, centripetally, it also involves the sourcing of knowledge, and developing of the latest skills, abilities, capacities, and proficiencies, internationally, for local implementation and use. That is why it remains extremely important that young students from Africa continue to study on-site in as many countries of the world as possible.

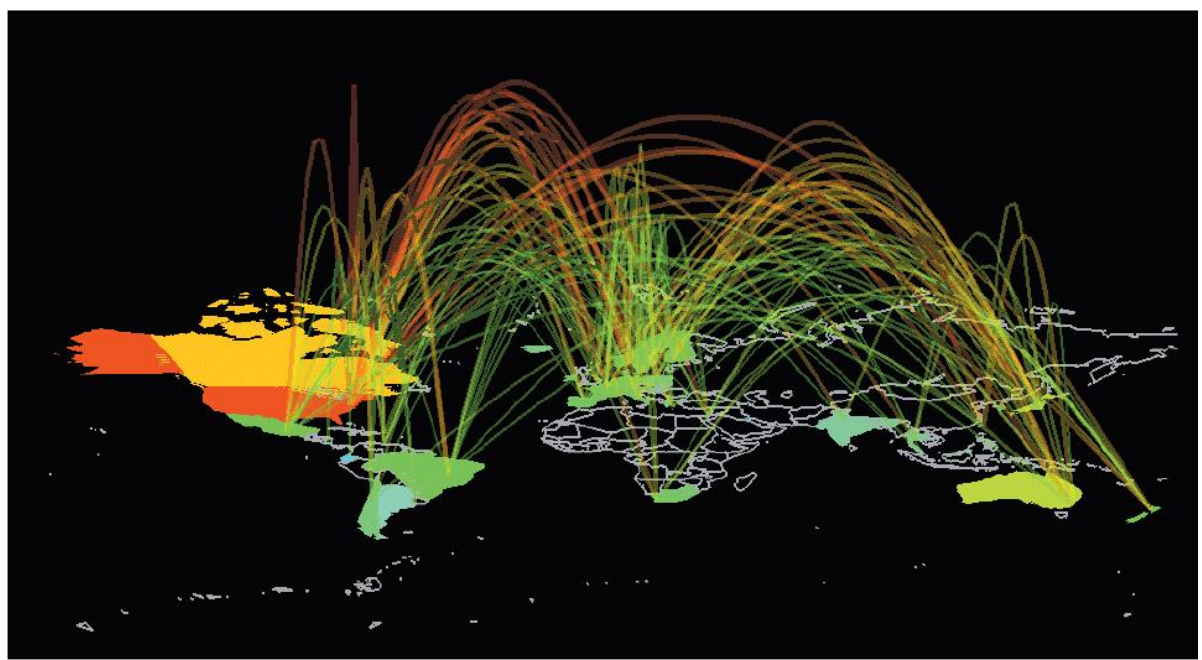

Image 4: The main inter-continental connections of information and data networks imaging connectivities inter-continentally, from 1996. In Internet traffic flows between countries in 1996, created by Stephen Eick and colleagues Ken Cox, Taosong $\mathrm{He}$ and Graham Wills, Bell Labs-Lucent Technologies / Visual Insight, from Dodge and Kitchin (2001).

And, fifth, an image of inter-continental connectivity, as produced by Parag Kanna, of the Instituto per Gli Studi di Politica Intrernazionale, Rome, 31 October 2018. The next, quite substantial quote is attached, to the site, and, even though a bit dated, we quote two Google- translated paragraphs from it.

\section{Connectivity will revolutionize geopolitics}

In the vision of Parag Khanna, expert in international relations and author of the best-selling Connectography: Mapping the Future of Global Civilization, connectivity creates a reality beyond the state 
dimension since in most of the world we have moved from vertically integrated empires to horizontally interdependent states. The megainfrastructures overcome the natural obstacles and those of political geography, and their mapping reveals that the era of organizing the world according to the political space (the ways in which the globe is divided from the legalistic point of view) is giving way to its functionalistic planning (how to use space according to utility). Borders define divisions through political geography; infrastructures inform us about connections through functional geography. And geopolitics is profoundly influenced by functional geography: transport routes, energy networks and internet infrastructure are the vehicles through which power is projected and influence is exercised.

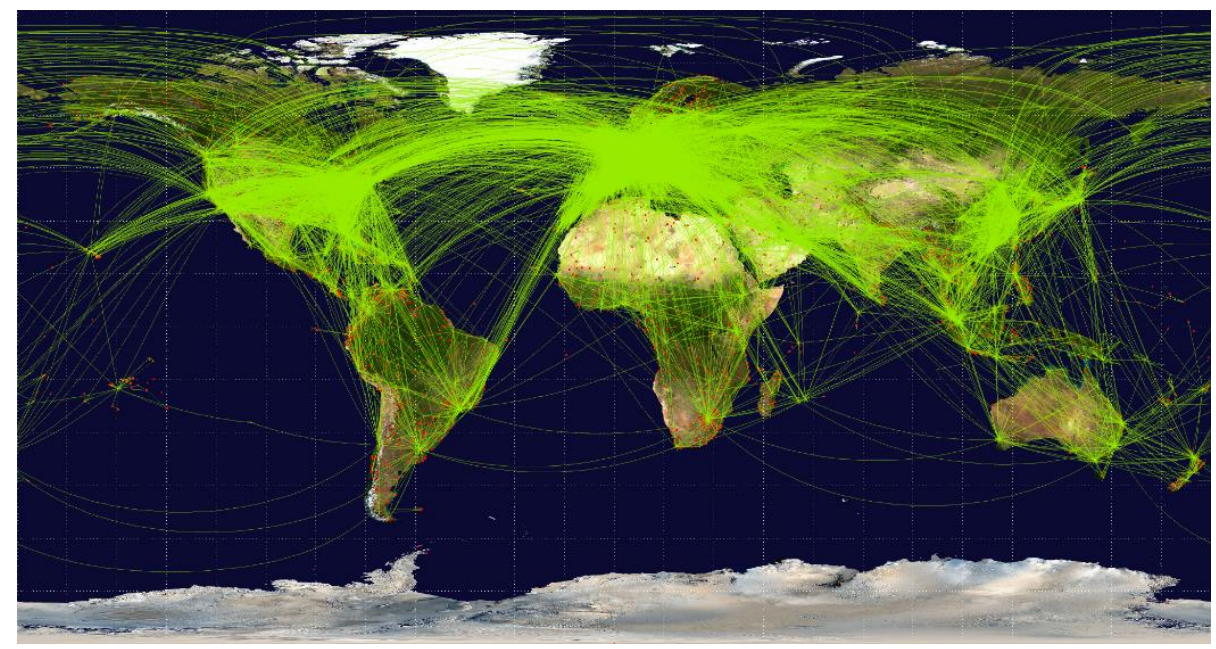

Image 5: A recent image on inter-continental connections of information and data networks imaging connectivities external to the continents. Cf. Kanna (2018), and also Chinese Academy of Cyberspace Studies (2017).

\section{How would you explain the relevance of connectivity in the medium to long term?}

Connectivity is the most revolutionary force that has emerged in human history and the trend with longer term durability. The use by 
humanity of all the technology available to build connectivity between cities, communities and individuals is simply an anthropological and central fact in the definition of human beings more than tribalism, the construction of borders and walls, or other instruments of separation. This is particularly important to remember in historical periods such as the current one, where the media and political scenario is dominated by discussions on economic protectionism and border protection. In reality, on the global level, the opposite is happening. In fact, we are witnessing an unfolding of physical connectivity of roads, railways, electricity grids, air routes, and fiber optic internet cabling at a level never reached. We have never achieved such a high degree of connectivity and at such a speed. Soon every single human being or family will have a cell phone. The question is not whether we will be connected, but how we will use this reality and who will benefit from it.

To this, finally, we add a sample of research on the opportunities and possibilities for intra-continental knowledge production in Africa, from 2017, based on 2011 data.

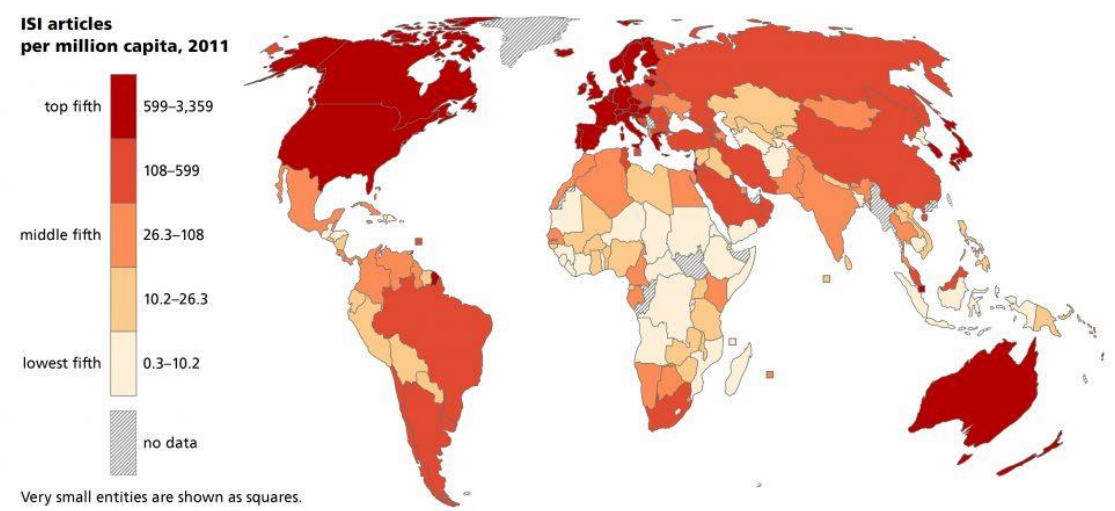

Image 6: Academic articles per million capita in 2011. Cf. Graham (2017). 


\section{Contextually-Relevant Knowledge Production via Knowledge Networks: Continentally and Trans- Continentally}

In this section, we just briefly summarise and overview a sample of functioning e-knowledge-production hubs, networks and related events, from the recent past, and present, that may be useful to develop and implement in our contexts.

Firstly, we copy a post from 2013, on the annual meeting of the African Studies Association in Baltimore, where, disciplines from History and Anthropology, to Public Health and Geography, reflected on processes and procedures of developing and involving the then more prominently emerging Digital Humanities. A central question concerns the number of panels that involved e-technologies. From our perspective, it is obvious, that very soon, presentations that do not involve e-technologies, might fall foul of becoming dated, if not locked into knowledge-power circles and blocks that have painted themselves into academic social corners outside democratic digital connectiveties and interactions.
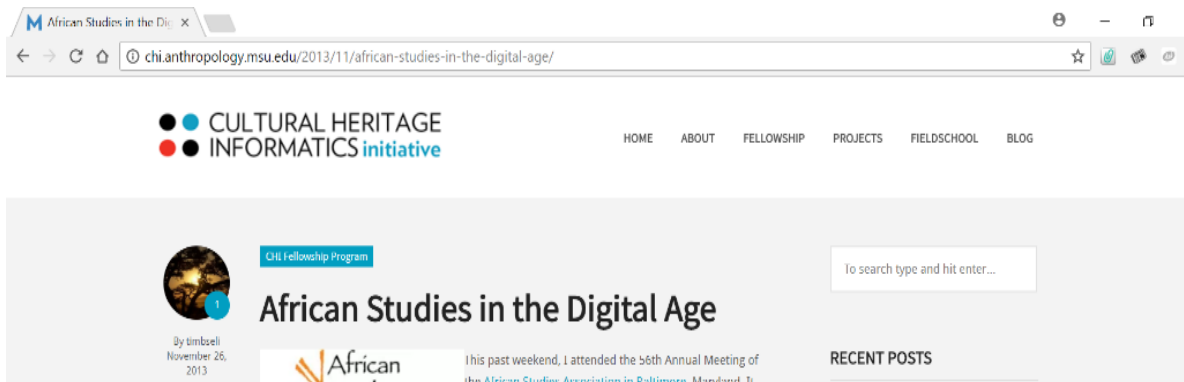

African Studies in the Digital Age

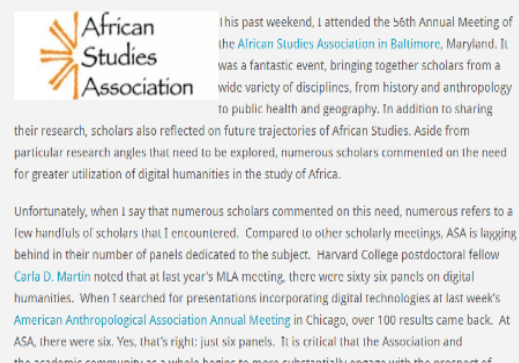

RECENT POSTS

Making as World-Making

Introducing tlise Dixon (CH.

(ellow)

Future Tense Digital Humanitics,

Technology, and the scholar

Cat memes and identity - Archives

and Divilal Worlds

4 무

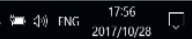

Image 7: Post on African Studies meeting in Baltimore in 2013. Available at: http://chi.anthropology.msu.edu/2013/11/african-studies-in-the-digital-age/ 
For the second, we copy a Call for Papers, by Roopika Risam and Kelly Baker Josephs, for their book, The Digital Black Atlantic, from April 2017, currently in production, in the Digital Humanities Series of the University of Minnesota Press. See also Risam's book, New Digital Worlds: Postcolonial Digital Humanities in Theory, Praxis and Pedagogy [2019], currently in preparation; and Glover, and Scott (2017), explaining the Digital Black Atlantic Project, as follows:

The Digital Black Atlantic Project (DBAP) was a multi-institutional and interdisciplinary working group that came together to invent a scholarly resource and digital platform for multimedia explorations and documentations of literary texts, visual documents, sites, moments, rituals and ceremonies, monuments and memorials, performances, and material objects emerging out of and concerning the Black Atlantic world ....

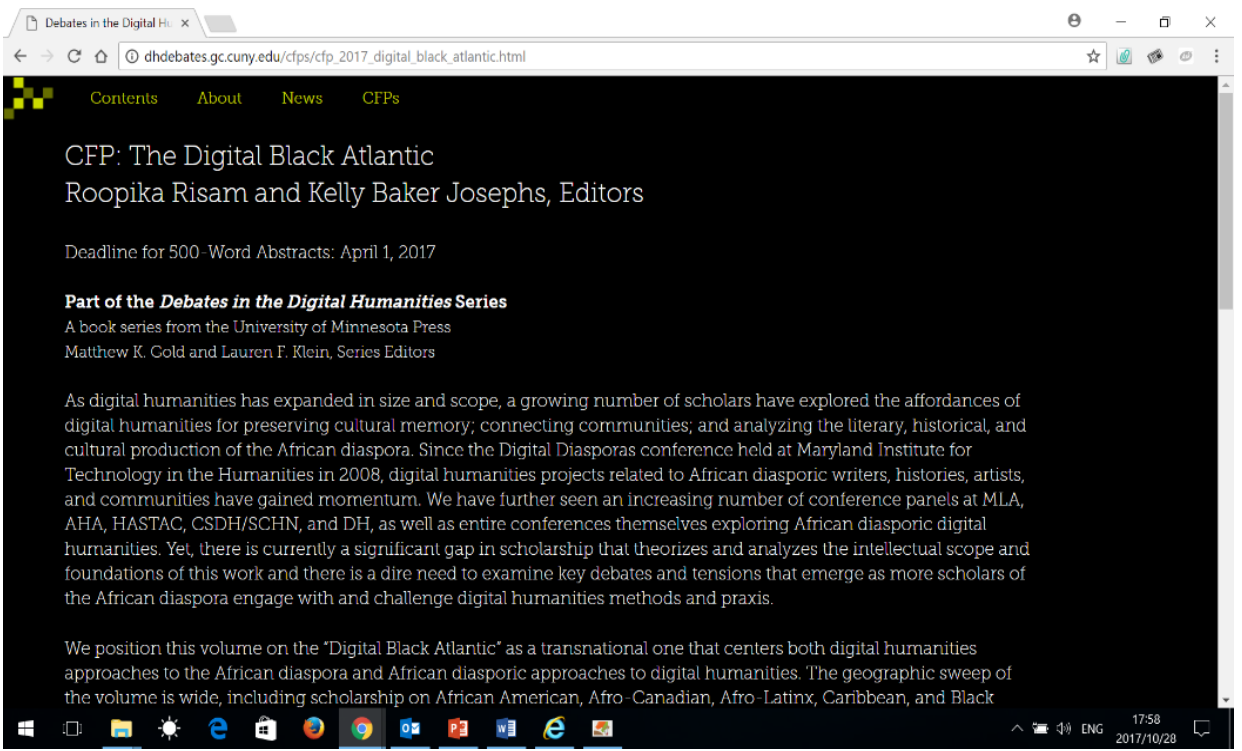

Image 8: Risam and Baker Joseph's Call for Papers for their book currently in production. 
The Quotation is available at:

https://www.socialdifference.columbia.edu/projects-/the-digital-blackatlantic.

The image is available at:

http://dhdebates.gc.cuny.edu/cfps/cfp_2017_digital_black_atlantic.html Cf. also, http://roopikarisam.com/digital-black-atlantic.html and, https://us.amazon.com/gp/product/0810138859/ref=dbs_a_def_rwt_bibl_vppi $\underline{\mathrm{i} 0}$

For the third, we have an image from Cleveland State University on the advancing of 'innovation' in the Digital Humanities, with a focus on the curation of African culture in the digital domain.

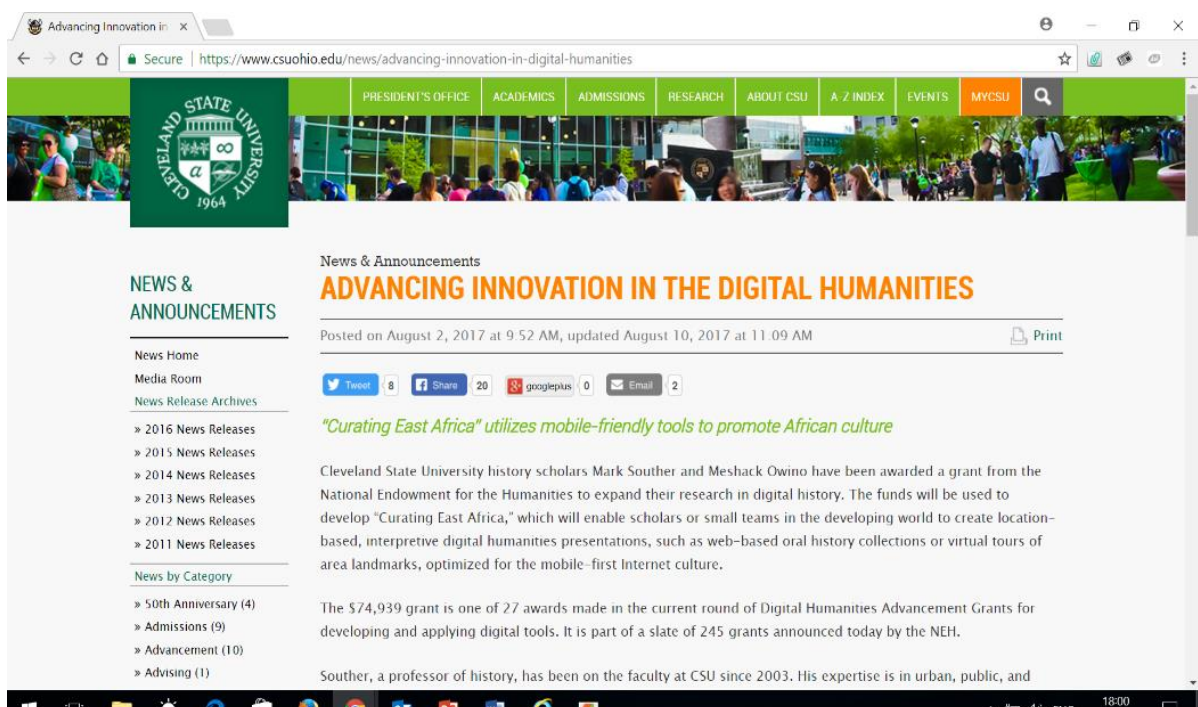

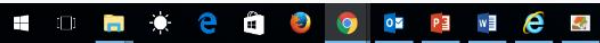

Image 9: Curating East Africa - Utilizing Mobile Friendly tools to promote African Culture. Available at: https://www.csuohio.edu/news/advancinginnovation-in-digital-humanities 
Fourthly, we have an image focused on African languages, and a linguistic metadata repository, the Ethnologue, mentioning the nearly billion people on the African continent, and its 2146 languages, of which 174 have institutional status. It was the subject of the European Summer University in Digital Humanities in Leipzig in 2017.

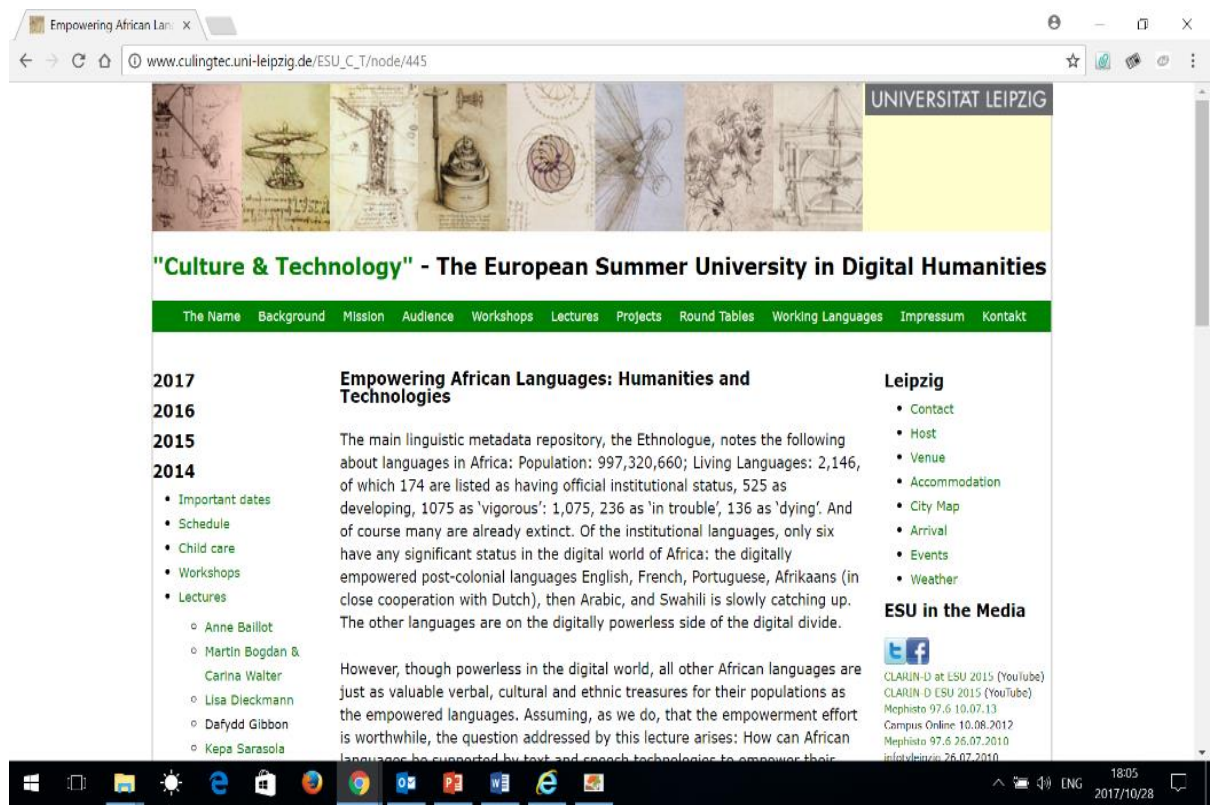

Image 10: Empowering African Languages: Humanities and Technologies. Available at: http://www.culingtec.uni-leipzig.de/ESU_C_T/node/445.

In the fifth and sixth places, we have two images of the United States' National Endowment of the Humanities (NEH), Office of the Digital Humanities, announcing 31 grants from the 2017 Office of the Digital Humanities, for the advancement of research in their Digital Humanities program, and more specifically, the Institutes for Advanced Topics in the Digital Humanities Program. Significantly, it indicates that these 31 grants, of the 245 grants awarded in 2017, were for the digitally integrated aspects of these projects. The sixth image, is the second from the Office of the Digital Humanities, introducing all 31 of the projects that received grants in 2017. 
The African Digital Humanities and Alternation on OJS

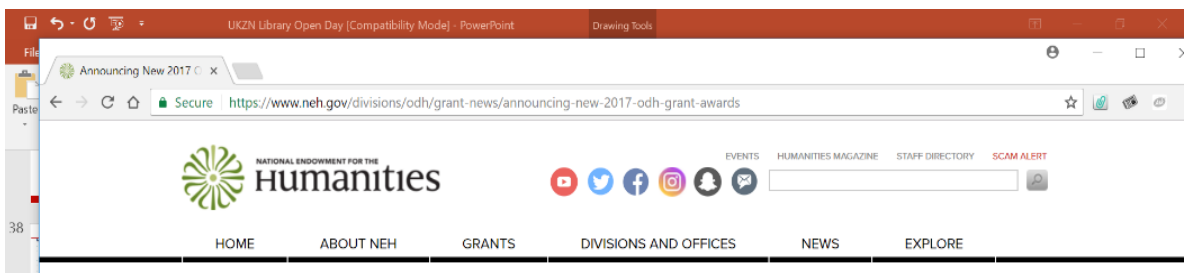

HOME / DIVISIONS AND OFFICES / OFFICE OF DIGITAL HUMANITES

OFFICE OF DIGITAL HUMANITIES

\begin{tabular}{|c|c|c|}
\hline \multicolumn{2}{|l|}{ DIVISIONS AND OFFICES HOME } & \multirow{2}{*}{$\begin{array}{l}\text { GRANT NEws } \\
\text { Announcing New } 2017 \text { ODH Grant Awards }\end{array}$} \\
\hline EDUCATION PROGRAMS & . & \\
\hline PRESERVATION AND ACCESS & r & AUGUST 2, 2017 I BY NEH STAFF \\
\hline PUBLIC PROGRAMS & v & It Like 147 Thoct G+ \\
\hline RESEARCH PROGRAMS & - & \\
\hline FEDERAL/STATE PARTNERSHIP & - & $\begin{array}{l}\text { The Office of Digital Humanities is pleased to announce } 31 \text { awards through our Digital Humanities } \\
\text { Advancement Grants program and our Institutes for Advanced Topics in the Digital Humanitics program. }\end{array}$ \\
\hline CHALLENGE GRANTS & $r$ & $\begin{array}{l}\text { These awards are part of a larger slate of } 245 \text { grants just announced by the NEH. Congratulations to all } \\
\text { the awardees as they begin these exciting new projects! }\end{array}$ \\
\hline
\end{tabular}

OFFICE OF DIGITAL

a 뭉

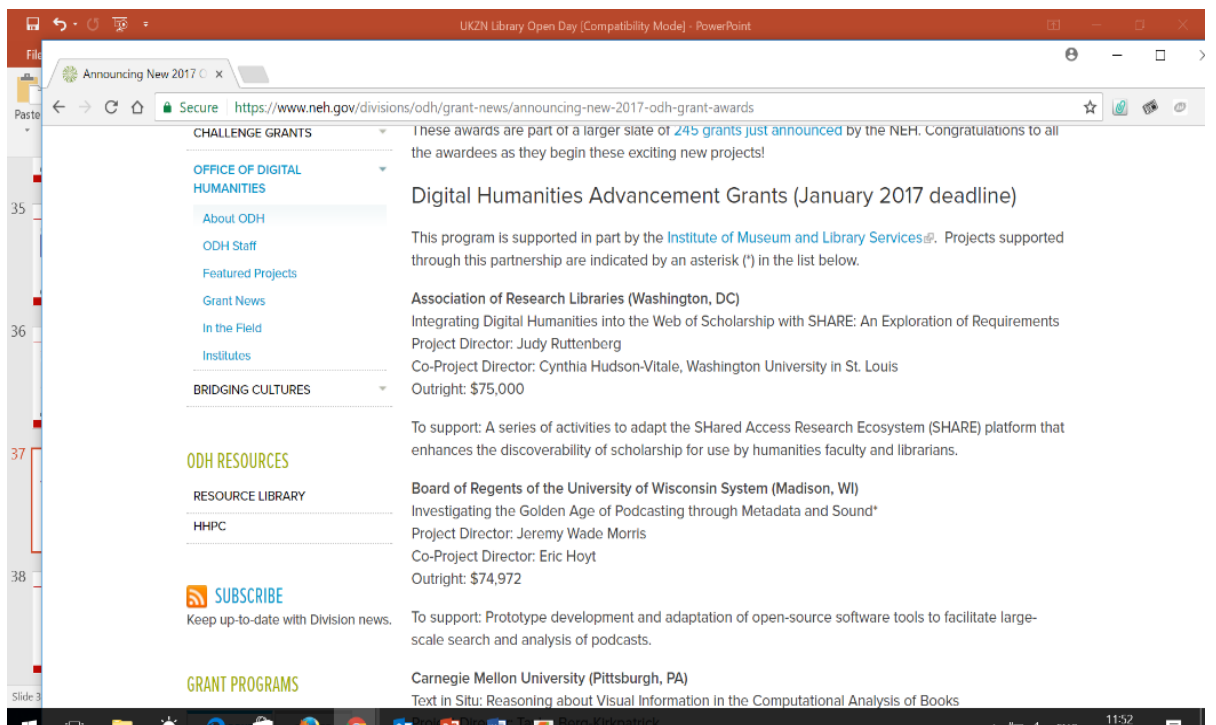

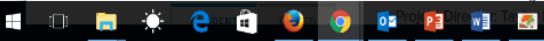

Image $11 \&$ 12: NEH, Office of the Digital Humanities web-announcement. Available at: https://www.neh.gov/divisions/odh/grant-news/announcingnew-2017-odh-grant-awards 
Seventh, we have a 2017 publication on the relationship between digital connectivity and digital content creation, focused on sub-Saharan Africa, by Ojanperä, Graham, Straumann, De Sabbata and Zook (2017).

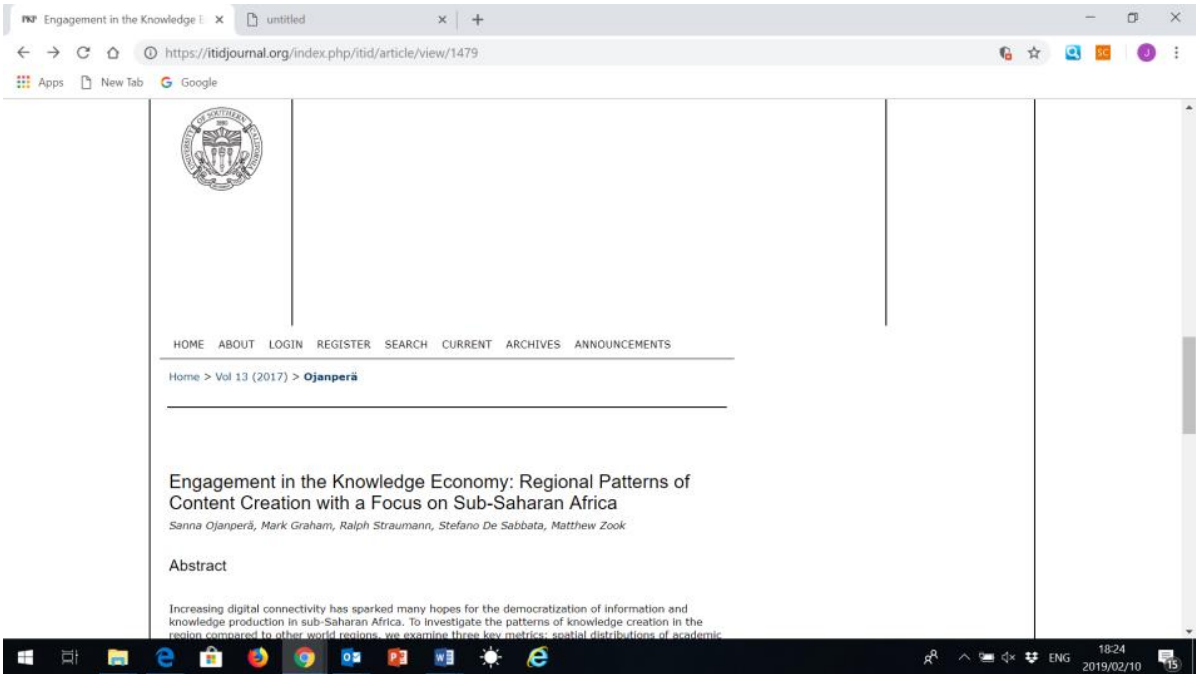

Image 14: Article, titled, 'Engagement in the Knowledge Economy: Regional Patterns of Content Creation with a Focus on Sub-Saharan Africa', by Ojanperä, Graham, Straumann, De Sabbata \& Zook (2017). Available at: https://itidjournal.org/index.php/itid/article/view/1479

In the eighth and final place, we have an image from Chain (2007), which, even though from a while back, represents some actual transcontinental organizations, then part of digital networks already. 


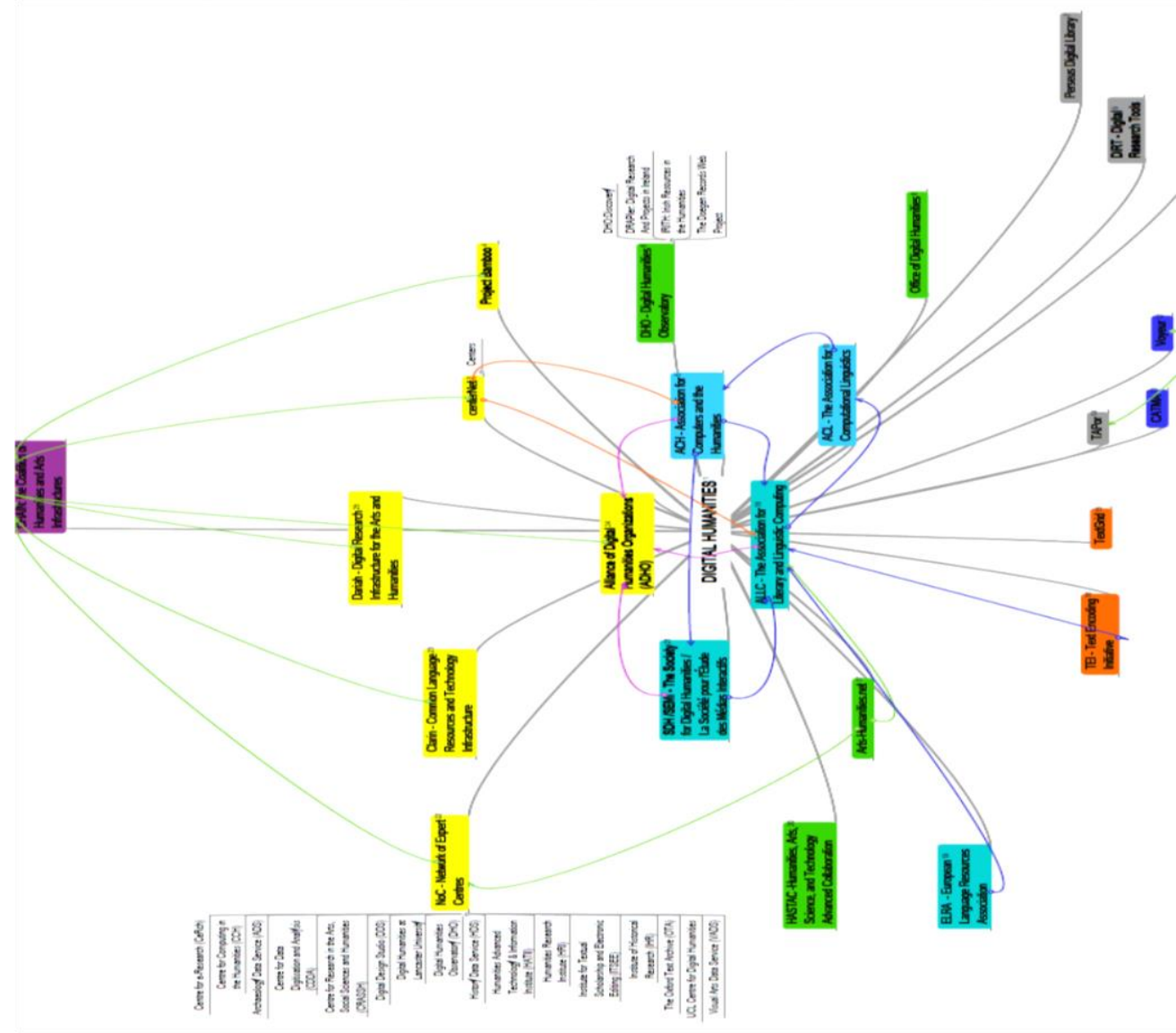

Image 15: Sample of trans-continental organizations, see Chain (c. 2007) at: http://eadh.org/sites/eadh.org/files/DIGITAL HUMANITIES.pdf 


\section{Conclusion}

By writing up his 'The Subject and Power' the way he did, and first published in 1982, two years before his death, Foucault sensed the importance the subject would acquire in the academic domain, in the post-communist, and postliberal, capitalist West politico-military-industrial complexes. That is why, he said, that his main focus for his research has not been 'power' and all the variety of historicized, and historicizeable, aspects that he uncovered through his historical researches. It was the subject. This notion of the subject that he focused on, was indeed, the subject that modernity produced, viewed from the perspective of the systems that produce or generate the knowledge formation $\rightarrow$ subjectivity, as well as the knowledge-formation $\rightarrow$ epistemic communication system $\rightarrow$ subjectivity articulations. In his triadic articulation though, Foucault reversed the dynamic, and asked these self-same questions of more than twenty years, from the perspective of the subjective, and more specifically, the embodied subject. It is this triadic understanding that we have used in the first article (pp. $8-30$ in this issue of Alternation) as well as this one, as template to not only think through, but also use as a springboard for starting the thinking of the future of the embodied, communication system(s), knowledge-producing African subject.

We have also showed in this article, how this could happen through 'innovation', and pointed to a very small sample of initiatives internationally, and mostly reported on during the last two years. In addition, we have provided a brief glimpse in images, as to the exponential explosion of the digital world internationally, not excluding the Digital Humanities. In this regard, we need to also recognize similar initiatives in South Africa, for instance by Wiser at the University of the Witwatersrand, and also at Stellenbosch University. The first three National Digital Humanities conferences have been organized, and Wiser has recently reported its allocation of 2019 Digital Humanities Research grants. We also note that, whereas the US's National Endowment of the Humanities (NEH), Office of the Digital Humanities, allocated 31 digitally-connected grants for research in 2017, this number has been more than doubled in 2018.

As is evident from these two articles, as based on Prof. J.A. Smit's Open Access lecture of 2017, as well as the explosion of initiatives in the Global Humanities globally, evidenced in our small sample, it is indicative that the processes and procedures being developed, centrally inform the research, as well as teaching and learning in the Humanities in South, and Southern Africa, as well as Africa more broadly afield. 
We have also sought to flag the ugly truth of the continued effects of apartheid and colonising blocks and knowledge formations. This cannot be wished away, and need to be confronted head-on. That is what has happened, for instance in the \#Rhodesmustfall, and \#Feesmustfall movements, amongst many others. We think that to think through the concerns of these movements, as these arise from embodied intellectual experiences, and as these relate to the epistemologies of the sciences, especially the Human Sciences, our theorizing and related modelling of Foucault, may provide one perspective to address these. We also think that, as one of the best theorised systems, of the notion of 'relevance', in a communication framework, Sperber and Wilson's theorizing of communicative relevance, may be helpful. We think that by linking it in an interdisciplinary space with Foucault's theorizing may be helpful, for purposes of knowledge production, in the constructivist theoretical framework.

Finally, we have sought to also articulate Foucault's triadic model, from the perspective of the subject, in the framework of the digital, ecommunication, and consequently, e-knowledge-power production. On the one hand, we have done this with a view to Castell's emphasis on the fact that, in our argument, national values, as enshrined in our Constitution, and Bill of Rights, should find material expression, and realization, in our institutions, and therefore in their shaping of society. As such, and since Foucault has not thought the subject as separate from the institution, but as populating the institutions, and being effected or impacted by the institutions, throughout his work, we should similarly think through the subject/ institution, as it is articulated as a combined 'unity', in its various uses of and impacts by the communication networks, as well as how it produces knowledge-power in the knowledge-power networks (KPNs), with their multiply impacts, that it forms.

On the other hand, we should think through this self-same system in terms of the digital era, digital knowledge-power (social) formations, and ultimately, the algorithm, to which we all are increasingly becoming exposed to. In this focus, and by putting Foucault's understanding to good use, in terms of the myriad of opportunities and challenges we are confronted with, not least with regard, to the dawn of the algorithm, we do believe that humanity, by collective cooperation, can enter a period of better management of not only ourselves, and the populations of the world, but also our environment. And, with all the new and innovative technologies, or 'instruments' we shall be better prepared and endowed, to do that through critically-constructive problematisations, and contextually-relevant production, and transformation of 
knowledge, articulated with evidence-based, empirical, contextually-relevant research-led teaching and learning (cf. Smit \& Chetty 2018 forthcoming). As such, we shall have to be attentive to the macro-, meso- and micro-physics of knowledge-power, and its impacts, not only for the improvement of the quality of life, and well-being, of humanity, but our planet as a whole. And, with regard to the labour challenges we face, we believe that the Digital Humanities, or eHumanities, and e-human, in collaboration with capital, our companies, and industries, may yet play a critical role. But that is a different story (cf. Nussbaum 2010, amongst others).

\section{References}

Abdulla, I. \& B.W. McArthur 2018. Government-to-Government eGovernment: A Case Study of Challenges Facing User Adoption in KwaZulu-Natal. Alternation 25,1: 154 - 186. https://doi.org/10.29086/2519-5476/2018/v25n1a8

African Studies Association in Baltimore. 2013. African Studies in the Digital Age. Available at: http://chi.anthropology.msu.edu/2013/11/africanstudies-in-the-digital-age/ (Accessed on 21 October 2017.)

Bailey, R. 1995. African Evidence for Three Proto-World Lexical Roots. Alternation 2,2: 155 - 138. Available at:

http://alternation.ukzn.ac.za/Files/docs/02.2/09\%20Bai.pdf

Berners-Lee, T. 1989. Tim Berners Lee's Proposal for an Information Management System. Available at: http://info.cern.ch/Proposal.html (Accessed on 22 October 2017.)

'Black Digital Humanities' and 'Post-Colonial Digital Humanities'. In Risam, R. \& K.B. Josephs (eds.): The Digital Black Atlantic. Available at: http://dhdebates.gc.cuny.edu/cfps/cfp_2017_digital_black_atlantic.html (Accessed on 21 October 2017.). Cf. also, http://roopikarisam.com/digitalblack-atlantic.html

Castells, M. 2009. Communication Power. Oxford: Oxford University Press. Cobb, S. 2013. Nussbaum, Martha C. (2010) Not for Profit: Why Democracy Needs the Humanities. Princeton. Culture Machine June: 1- 6. Available at: (Accessed on 21 October 2017.) https://www.culturemachine.net/index.php/cm/article/download/501/518 https://doi.org/10.1179/030801805X25909 
Chinese Academy of Cyberspace Studies (ed.) 2017. World Internet Development Report 2017. Ping, P. (trans.). Beijing, China: Publishing House of Electronic Industry, \& Springer.

Curating East Africa - Utilizing Mobile Friendly Tools to Promote African Culture. Available at: https://www.csuohio.edu/news/advancinginnovation-in-digital-humanities (Accessed on 21 October 2017.)

Dodge, M. \& R. Kitchin 2001. Atlas of Cyberspace. Released under a Creative Commons. Available at:

https://issuu.com/cyberbadger/docs/atlas_of_cyberspace

Empowering African Languages: Humanities and Technologies. Available at: http://www.culingtec.uni-leipzig.de/ESU_C_T/node/445. (Accessed on 21 October 2017.)

Foucault, M. 1982. The Subject and Power. Critical Inquiry 8,4, Summer: 777795. Available at:

https://www.jstor.org/stable/1343197?seq=1\#page_scan_tab_contents (Accessed on 21 October 2017.)

Glover, K.L. \& D. Scott 2017. The Digital Black Atlantic. Center of the Study for Social Difference, Columbia. Available at:

https://www.socialdifference.columbia.edu/projects-/the-digital-blackatlantic.

Graham, M 2017. Mapping the Global Knowledge Economy. Available at: https://geonet.oii.ox.ac.uk/blog/mapping-the-global-knowledge-economy/

Hall, G. 2011. The Digital Humanities beyond Computing: A Postscript. Culture Machine 12:1 - 11. Available at:

http://www.culturemachine.net/index.php/cm/article/view/441/471.

(Accessed on 21 October 2017.)

Kanna, P. 2018. Connectography: Mapping the Future of Global Civilization. London: Vintage. Available at:

https://www.ispionline.it/it/pubblicazione/parag-khanna-la-connettivitarivoluzionera-il-futuro-della-geopolitica-21511

Katz, S.N. 2005. Why Technology Matters: The Humanities in the Twentyfirst Century. Interdisciplinary Science Reviews 30,2: 105 - 118. Available: http://files.camolinaro.net/200000378-895438a4dc/ISR Technology.pdf (Accessed on 21 October 2017.) https://doi.org/10.1179/030801805X25909

Klopper, R. 2005a. The Evolution of Human Communication from Nonverbal Communication to Electronic Communications. Alternation 12,2a: 107 - 
120. Available at:

http://alternation.ukzn.ac.za/Files/docs/12.1a/06\%20Klo.pdf

Klopper, R. 2005b. Future Communications: Mobile Communications, Cybernetics, Neuro-Informatics and Beyond. Alternation 12,1a: 121 - 144. Available at:

http://alternation.ukzn.ac.za/Files/docs/12.1a/07\%20Klo.pdf

Kuhn, T. 1962. The Structure of Scientific Revolutions. Chicago: University of Chicago Press. Available at:

https://projektintegracija.pravo.hr/_download/repository/Kuhn_Structure_ of_Scientific_Revolutions.pdf

Nussbaum, M.C. 2010. Not for Profit: Why Democracy Needs the Humanities. Princeton. Available at:

http://www.filosofia.unimi.it/zucchi/NuoviFile/(Public\%20square\%20(Pri nceton, \%20N.J.))\%20Martha\%20C.\%20Nussbaum-

Not\%20For\%20Profit_\%20Why\%20Democracy\%20Needs\%20the $\% 20 \mathrm{H}$ umanities\%20(The\%20Public\%20Square)\%20\%20-

Princeton\%20University\%20Press\%20(2010).pdf

(Accessed on 21 October 2017.)

Office of Digital Humanities. 2017. Announcing New 2017 ODH Grant Awards. National Endowment for the Humanities. Available at: https://www.neh.gov/divisions/odh/grant-news/announcing-new-2017odh-grant-awards. (Accessed on 21 October 2017.)

Ojanperä, S., M. Graham, R.K. Straumann, S. De Sabbata \& M. Zook 2017. Engagement in the Knowledge Economy: Regional Patterns of Content Creation with a Focus on Sub-Saharan Africa. Information Technologies \& International Development 13:33 - 51. Available at:

https://itidjournal.org/index.php/itid/article/view/1479

Risam, R. [2019]. New Digital Worlds: Postcolonial Digital Humanities in Theory, Praxis and Pedagogy. Evanston, Ill: Northwestern University Press.

https://us.amazon.com/gp/product/0810138859/ref=dbs a def rwt bibl v ppi_i0

Smit, J.A. 2009. The 'Dis-embodied Mind' and Religion. Alternation Special Edition 3: 354 - 391; Available at:

http://alternation.ukzn.ac.za/Files/docs/Alternation\%20Spec\%20Ed\%203 \%20Pdfs/17\%20Smit\%20FIN.pdf

Smit, J.A. 2017. \#DecolonialEnlightenment and Education. Alternation 24,2: 
253 - 311. DOI: https://doi.org/10.29086/2519-5476/2017/v24n2a13

Smit, J.A. \& D. Chetty 2018a. 23/ 25 Years of Alternation, and the African

Digital Humanities: Capacity, Communication, and Knowledge-Power.

Alternation 25,1: 8 - 30.

https://doi.org/10.29086/2519-5476/2018/v25n1a2

Smit, J.A. \& D. Chetty 2018b. Designing Equitable Foundations for Open

Knowledge: Access, Freedom \& e/Quality. Alternation Special Edition 23: $8-33$.

https://doi.org/10.29086/2519-5476/2018/v25n1a15

Sperber, D. [1975] 1979. Rethinking Symbolism. Morton, A. (trans.). Cambridge:

Cambridge University Press.

Sperber, D. \& D. Wilson [1986] 1996. Relevance. Communication and Cognition. Oxford: Blackwell.

Sperber, D. 2002. Explaining Culture: A Naturalistic Approach. Malden, Mass: Blackwell Publishing. Available at:

https://monoskop.org/images/0/05/Sperber Dan Explaining Culture A Nat uralistic_Approach_1996.pdf

Wilson, D. \& D. Sperber 2012. Meaning and Relevance. Cambridge: Cambridge University Press.

https://doi.org/10.1017/CBO9781139028370

Stahl, G. 2000. A Model of Collaborative Knowledge-Building. In Fishman, B $\&$ S. O-Connor-Divelbiss (eds.): Fourth International Conference of the Learning Sciences. Mahwah, NJ: Erlbaum. Available at:

http://www.umich.edu/ icls/proceedings/pdf/Stahl.pdf. (Accessed on 21 October 2017.)

Johannes A. Smit Editor-in-Chief: Alternation University of KwaZulu-Natal smitj@ukzn.ac.za

Denzil Chetty Assistant Editor: Alternation College of Human Sciences University of South Africa chettd@ukzn.ac.za 